\title{
An Imaginary Taiwan From a Composer in China -A Case Study of Taiwan Bangzi Opera
}

\author{
Ming-Hui Ma \\ Nanhua University, Chiayi County, Taiwan
}

\begin{abstract}
Taiwan Bangzi Opera is a branch of Henan Bangzi Opera in Henan, which was transmitted from China to Taiwan within the armies under a political and historical circumstance around 1947. As the trend of localisation in these ten years becomes obvious, several localised performances are created; however, the composers in China do not understand the music culture in Taiwan, so some interesting phenomenon can be found between an imaginary Taiwan from their viewpoints and the real culture in Taiwan. The Sorceress Bride is a performance which adapted so-called the aboriginal tune in 2012, and it arises several issues for further discussion.
\end{abstract}

Keywords: Taiwan Bangzi Opera, Sorceress Bride, localisation, Evergreen Mountains, Dancing to the Moon

\section{Introduction}

This paper is going to discuss about an imaginary Taiwan from the viewpoint of a Chinese composer in a performance of Taiwan Bangzi Opera from two aspects through a comparison. These two aspects are the purposes and reflections from this tune used in this performance. The first aspect focuses on the two main purposes of this tune from the viewpoint of this Chinese composer (Zuo Qi-wei) and the second aspect discusses the three reflections from the tune used in this performance through a comparison, including the real tune in the indigenous culture in Taiwan, and the analysis of the discrepancy between the putative and real music in the minority groups in Taiwan. Each aspect will be supported with relevant music examples.

\section{Background Knowledge}

Taiwan Bangzi Opera is a branch of Henan Bangzi Opera (a genre of Chinese operas), which was transmitted from Henan Province in Mainland China under a historical circumstance within the armies during 1947-1949. Before the trend of localisation of Taiwan Bangzi Opera in these ten years, this genre had been called Henan Bangzi Opera in Taiwan for more than fifty years. Recently, the official name of this genre is renamed as Taiwan Bangzi Opera. In order to develop new style of Taiwan Bangzi Opera compared to Henan Bangzi Opera in China, this performing group will commission some composers to create some new programmes to demonstrate its ability in development in Taiwan. Among these compositions, all of them are from China, because there is no professional education institution for composer in Bangzi Opera in Taiwan; however, the scripts can be native stories in Taiwan or some adaptions from other programmes.

Ming-Hui Ma, Ph.D. at Sydney Conservatorium of Music, University of Sydney, Assistant professor at Nanhua University. 


\section{Discussion and Purposes}

The Sorceress Bride (2012) is one of these localised performances in Taiwan (see Figure 1). In order to localise this opera, the Chinese composer (Zuo Qi-wei) intended to use a widespread Taiwanese tune both in China and Taiwan to establish the suitable atmosphere in this performance. According to the interview with her, she selected this so-called popular tune about aboriginal music in Taiwan for two purposes: setting up the atmosphere of a putative aboriginal tribe and localising this performance.

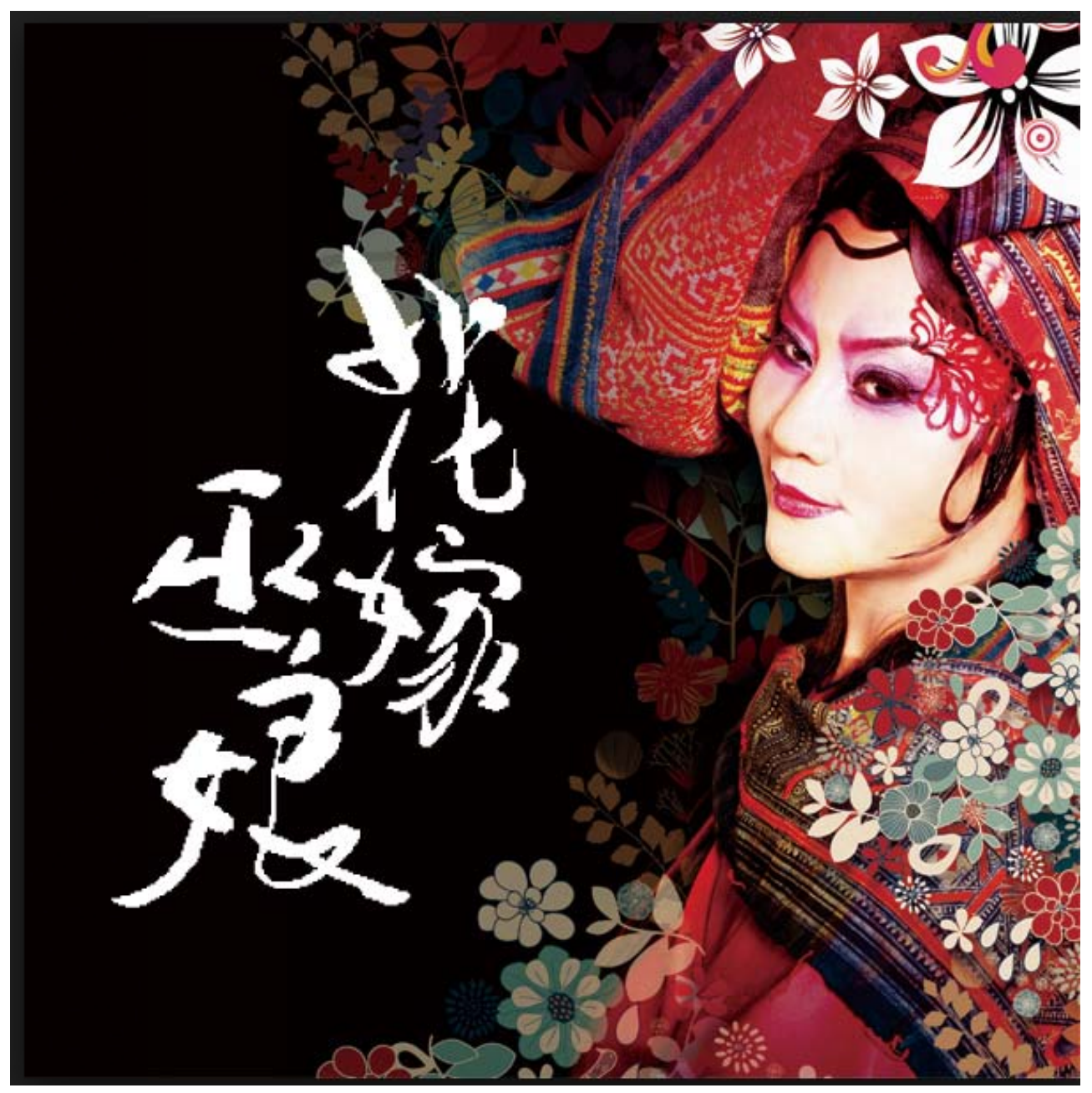

Figure 1. The poster of the Sorceress Bride.

The story of this opera describes a love story in an imaginary minority group (see Figure 2). In order to fulfill the demands of this story, the composer decided to utilise a tune in aboriginal tribes in Taiwan based on her knowledge. Furthermore, the usage of this tune in Taiwan can help localise this opera originated from China. 


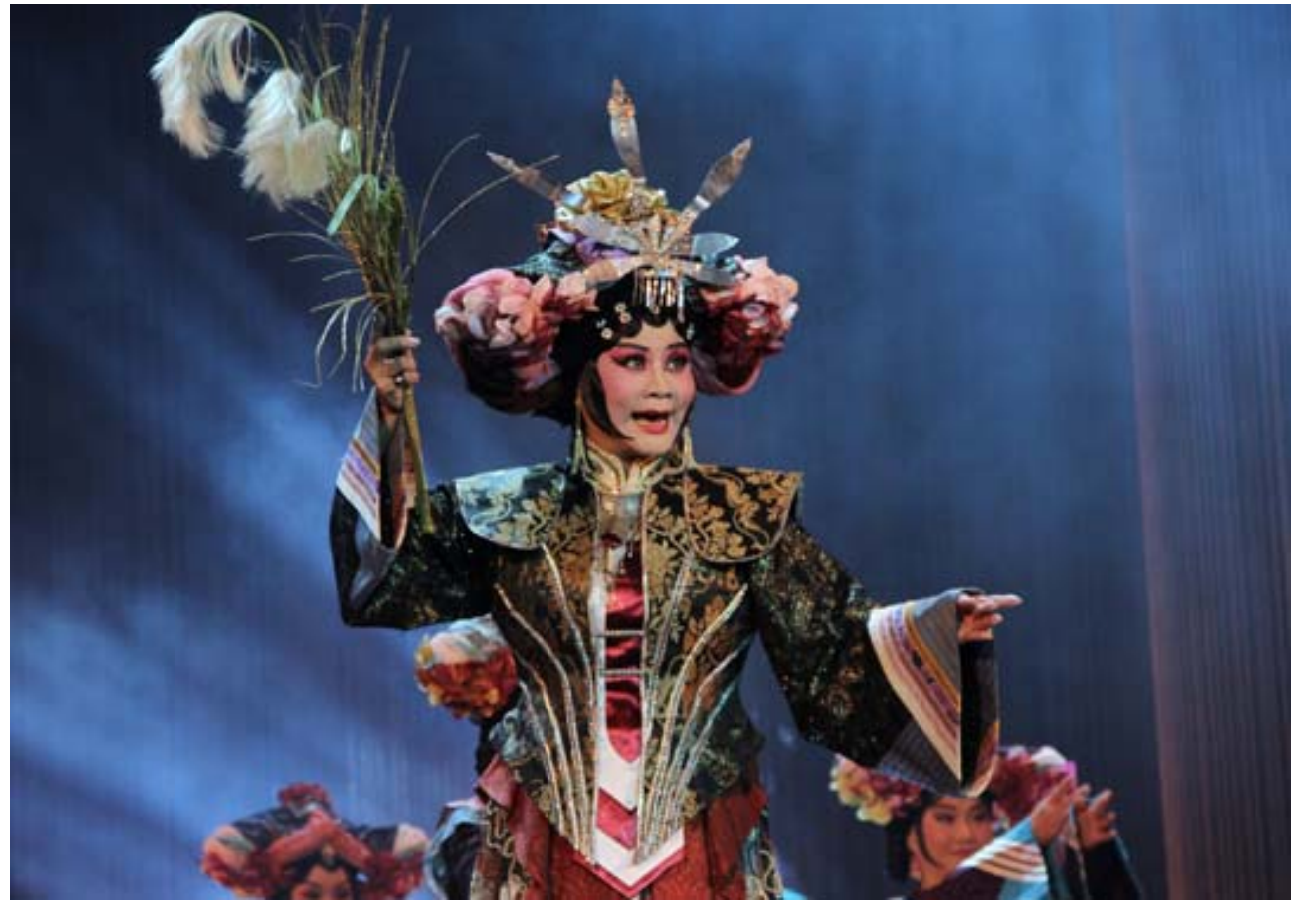

Figure 2. The costume of the Sorceress Bride on the stage.

While analysing how the composer utilises this tune in this opera, three methods can be found: prelude, interlude, and introductory or ending phrases. According to the interview with this Chinese composer, she used one popular indigenous tune to construct a putative environment on the stage, projecting her imaginary Taiwan in this performance. When it comes to music she arranged, it works effectively to establish this suitable atmosphere. The original tune she used is the phrases in Evergreen Mountains, and this film song describes the environment in the village and the appearance of one aboriginal tribe (Tsou Tribe) in Ali Mountains in Taiwan (see Figure 3).

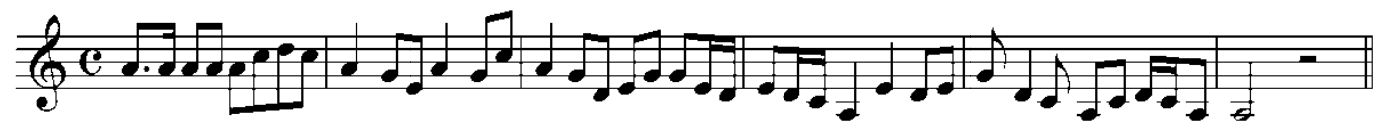

Figure 3. Music example 1: The original tune of Evergreen Mountains from Zuo Qi-wei. ${ }^{1}$

Three kinds of arrangements by her skills in composition can be illustrated by relevant music examples. Music example 2 (see Figure 4) is the prelude of this performance and the main purpose is to remind the audience that this story is from a minority tribe in a remote area at the beginning of this performance.

\footnotetext{
${ }^{1}$ See https://www.youtube.com/watch?v=uZOovTyNQ1Q.
} 


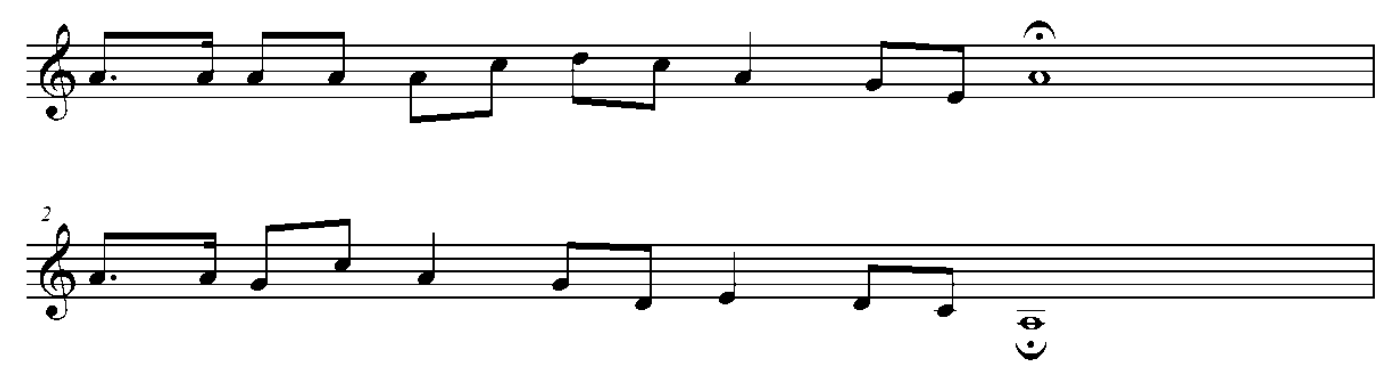

Figure 4. Music example 2: The prelude in the Sorceress Bride. ${ }^{2}$

Music example 3 is another example to illustrate how this composer used this tune as an introductory section in 2/4 and connected to traditional singing section in $4 / 4$. From bar 1 to 23 , it is the rearrangement of this tune and the section from bar 24 is the traditional introductory section in Taiwan Bangzi (see Figure 5).
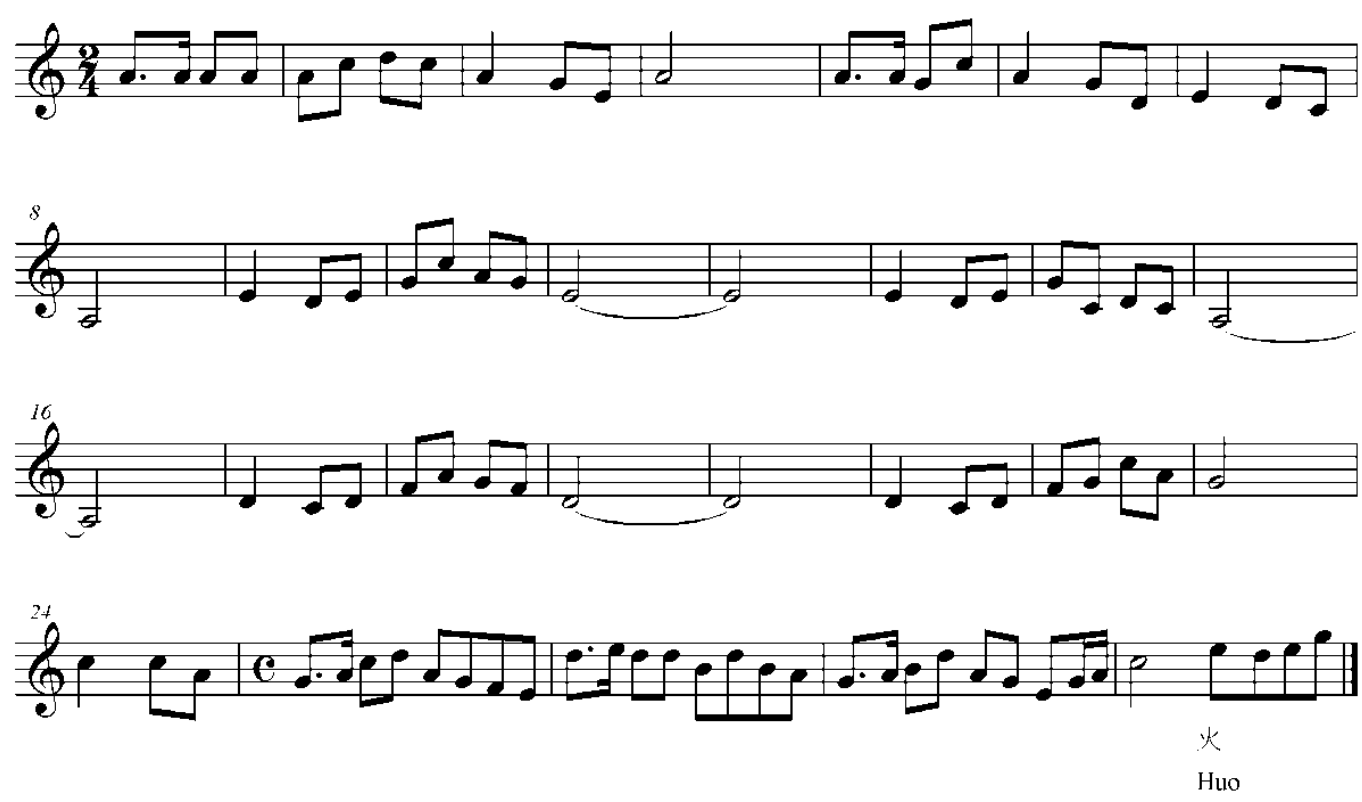

Figure 5. Music example 3: Introductory section with traditional singing section. ${ }^{3}$

In music example 4, it is evident that this tune is applied as the introduction and ending sections in a singing section in a free tempo, which reveals a contemporary hybrid style in Taiwan Bangzi Opera (see Figure $6)$.

\footnotetext{
${ }^{2}$ See https://www.youtube.com/watch?v=GxvgVzCqx4o.

${ }^{3}$ For other live performance clips and interviews, please see https://www.youtube.com/watch?v=p3Yw92aHu24. See https://www.youtube.com/watch?v=RNucMwoDUCY. See https://www.youtube.com/watch?v=DlmNgiVmA_c.
} 


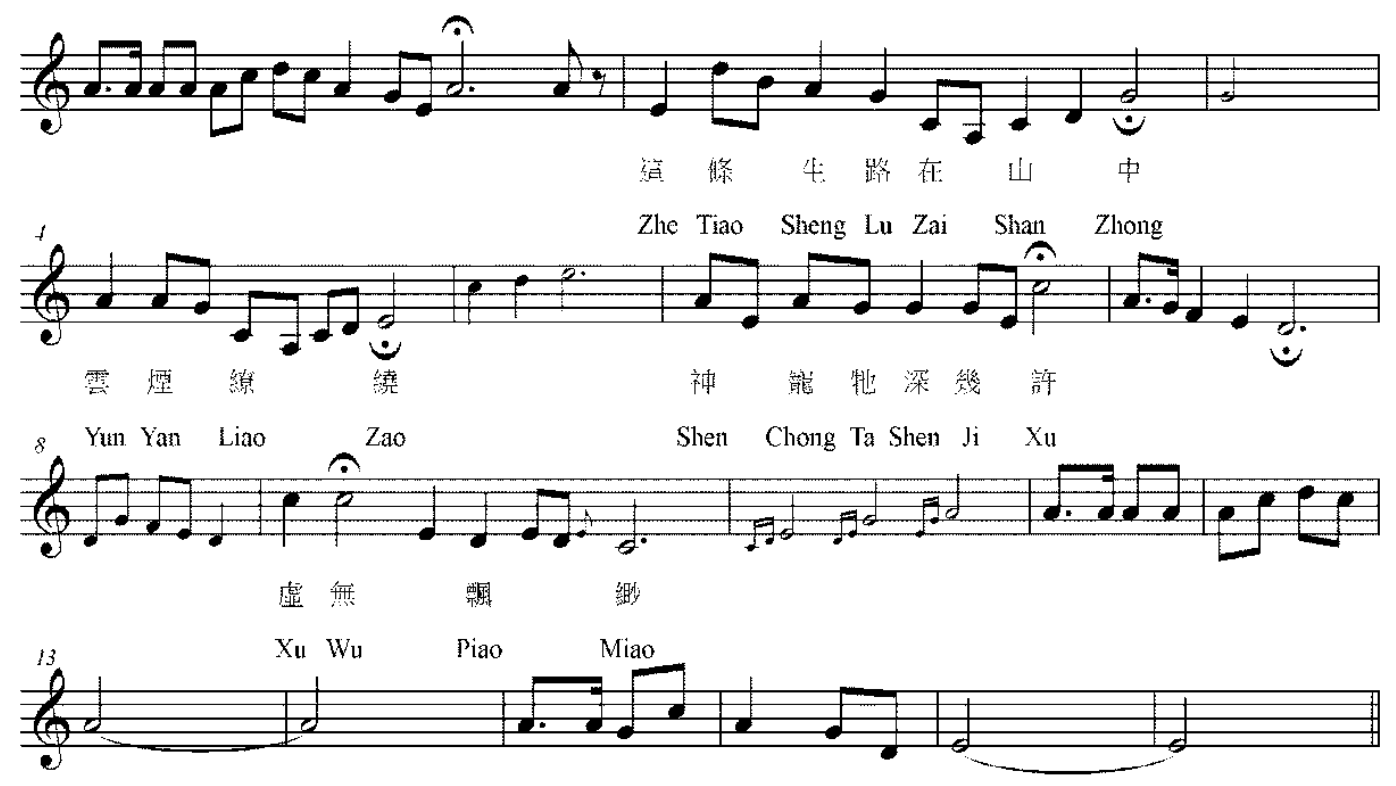

Figure 6. Music example 4: The introduction and ending sections in a singing section.

In addition to these arrangements above, this tune is used as the interlude (ending phrase) between Act Five and Six (music example 5) (see Figure 7).

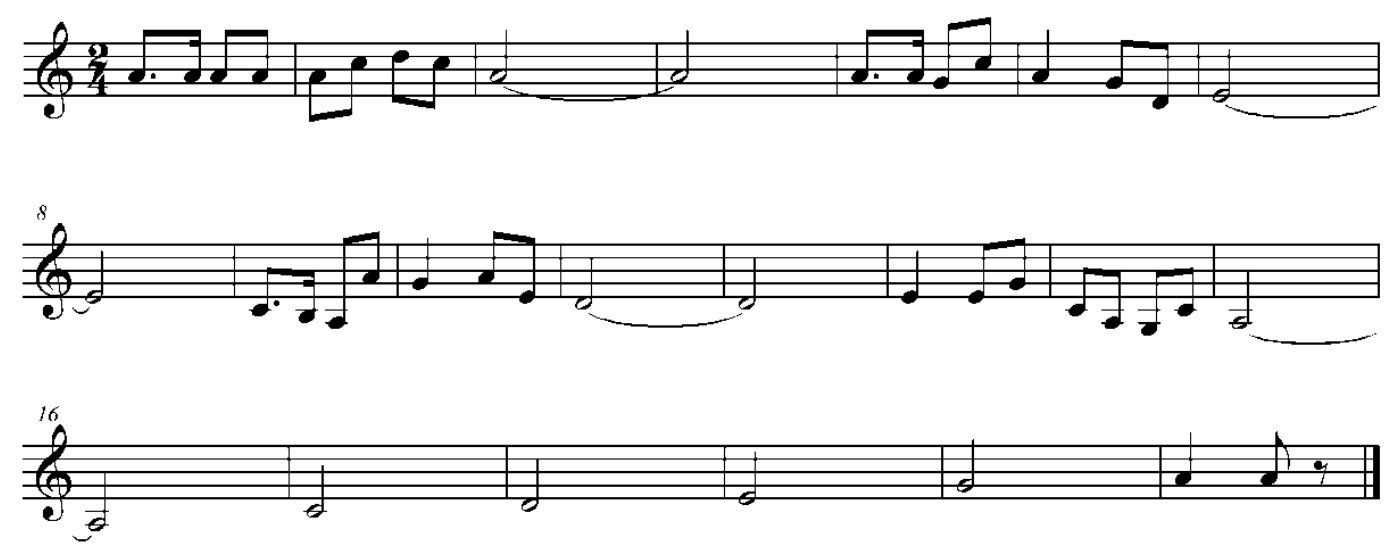

Figure 7. Music example 5: Interlude in the performance.

In music examples 6, 7 and 8, it is strikingly obvious that before the singing section, the introductory part can be divided into two small parts (bar $1 \& 2$, bar $3 \& 4$ ). The phrase from bar 1 to 2 is the fragment phrase from the tune, while the motive from bar 3 to 4 is the traditional introductory phrase in Taiwan Bangzi Opera (see Figures 8, 9 and 10).

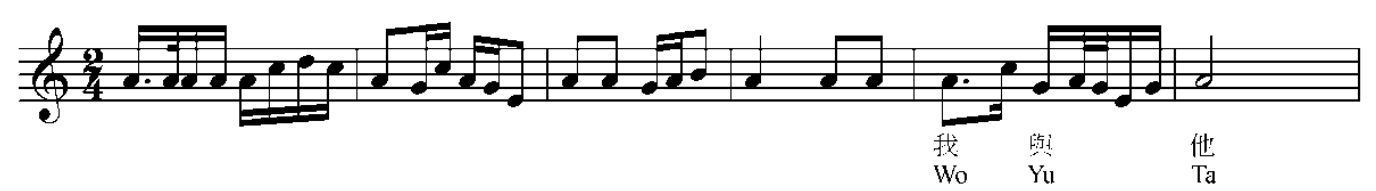

Figure 8. Music example 6: An introductory phrase. 


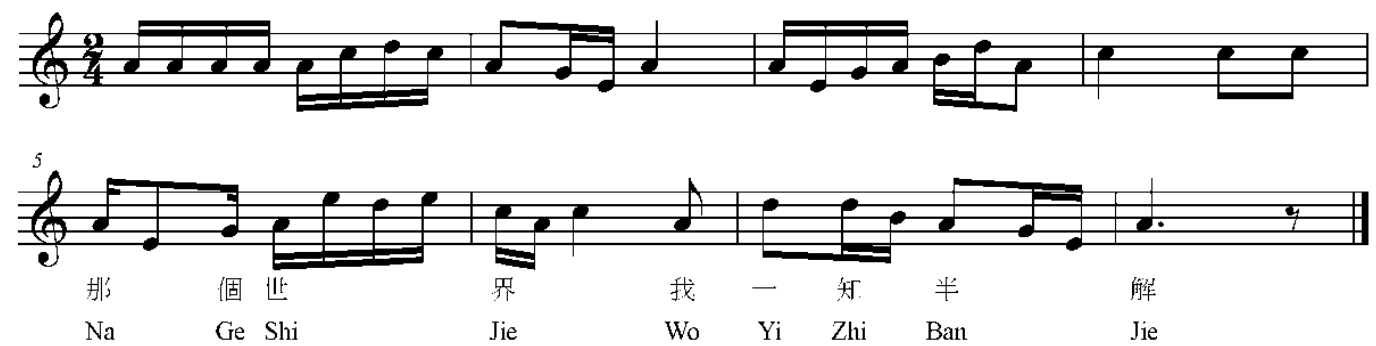

Figure 9. Music example 7: An introductory phrase.

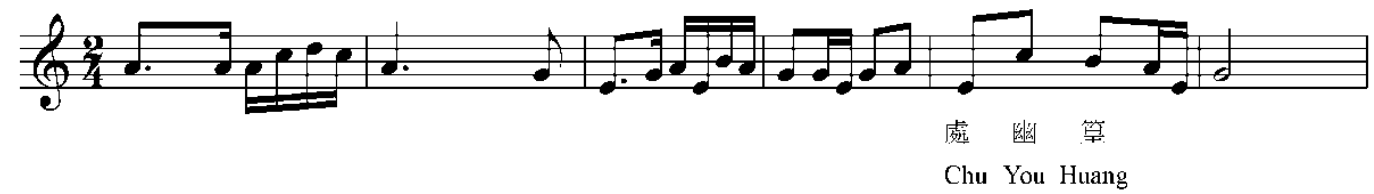

Figure 10. Music example 8: An introductory phrase.

From the demonstration of these music examples, it is evident that the composing skills by this compose is quite mature, because she can integrate another tune into traditional singing smoothly to fulfill the main goal she intends to achieve. By listening to these arrangements in this performance, the audience can be aware of the tune, which functions as the connection between their experience in the recognition of tune in Taiwan and the imaginary story of a minority group in the performance.

\section{Discussion and Reflections}

Although this composer can arrange this tune by her professional skills in composition, some issues can be addressed by scrutinising the melody she used in the performance, and these issues reveal that some misunderstanding about the aboriginal music in Taiwan resulted from insufficient information by the division between Taiwan and Mainland China under a historical and political condition and the influence of the media and propaganda.

First, before this Chinese composer used this tune, she did not go to Taiwan for her fieldwork to understand aboriginal music in Taiwan. What she can find is a popular film song in a song book for folksongs in China, and the name of the tune is Evergreen Mountains; however, the main melody she used in the performance is not the main theme in this film song, but rather a connective phrase between two sections. Furthermore, this song (Evergreen Mountains) is not the original music in an aboriginal tribe in Taiwan while comparing the description of this aboriginal tribe in Evergreen Mountains with the real songs in Tsou Tribe in Ali Mountains. Music example 9 (see Figure 11) is the original tune of Evergreen Mountains and the connective phrase is music example 1. With the help of the promotion by mass media, Evergreen Mountains becomes the most popular song about aboriginal music in China and Taiwan. By using this tune in the performance, it can fulfill the demand of establishing the atmosphere of an imaginary aboriginal tribe. 


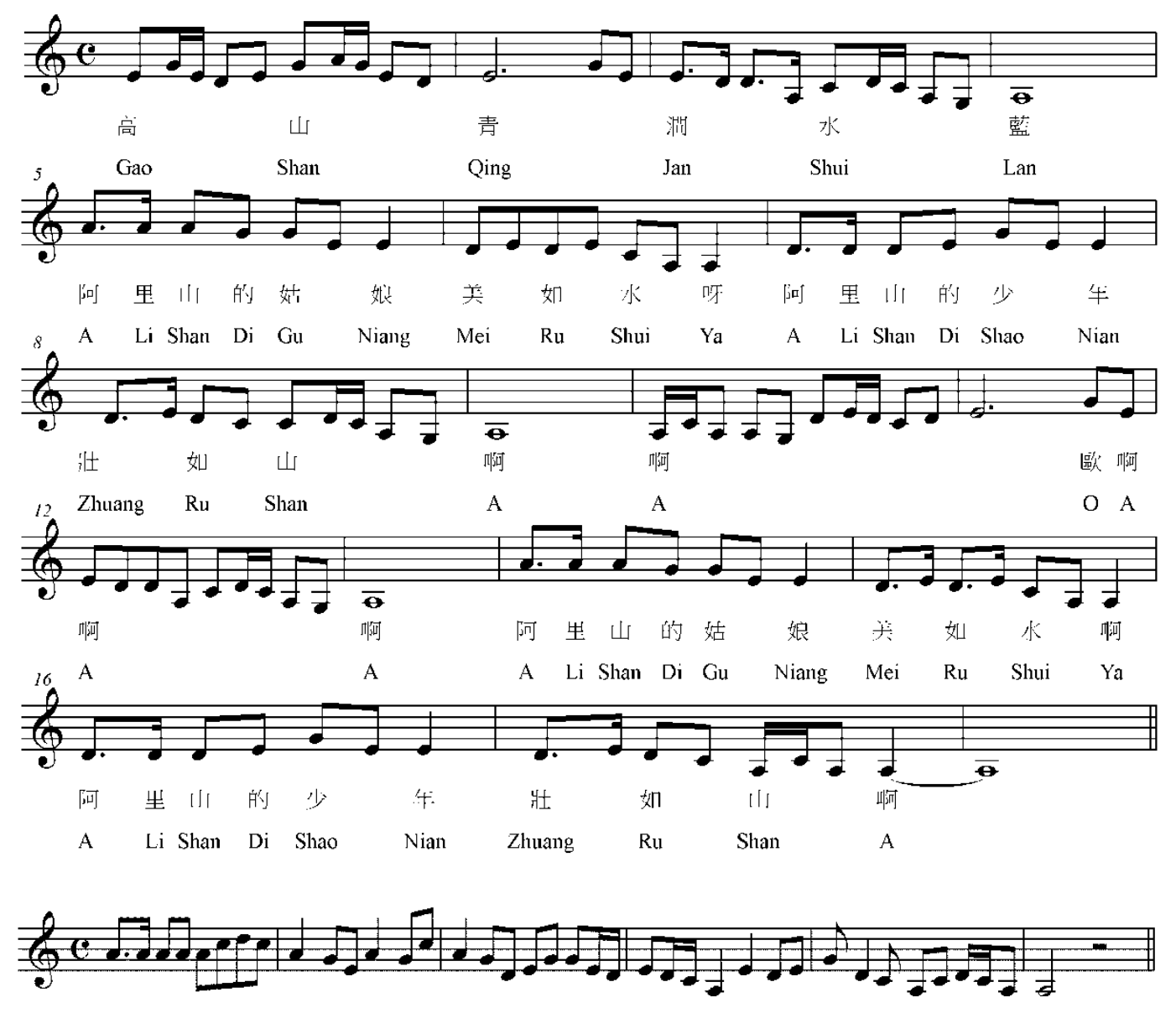

Figure 11. Music example 9: Evergreen Mountains and the connective phrase. ${ }^{4}$

Music example 10 (see Figure 12) is a common tune of Tsou tribe in Ali Mountains, and it is different from the tune of Evergreen Mountains in terms of music characteristic, although the song was composed by another composer for a film based on his impression when he travelled to Ali Mountains. From a comparison, it is evident that there is no strong connection between these two tunes. Because of this discrepancy between these two songs about the aboriginal music in Taiwan, this Chinese composer used her misunderstanding to construct an imaginary Taiwan atmosphere in this performance. In music example 9, it is clear that the phrase is a pentatonic scale and this is the main musical characteristic; while in music example 10, the interval of the fourth (E-A, Mi-La) is the main music characteristic. As a result, there is obvious and persuasive relationship between these two music examples in terms of the music characteristics.

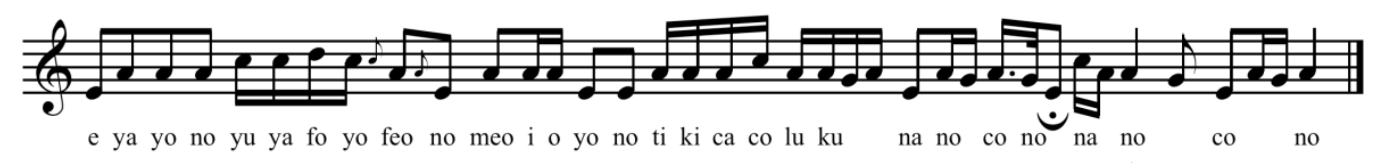

Figure 12. Music example 10: A song of catching crabs in Tsou Tribe. ${ }^{5}$

\footnotetext{
${ }^{4}$ See https://www.youtube.com/watch?v=uZOovTyNQ1Q.

${ }^{5}$ See https://www.youtube.com/watch?v=r9tTF09-nms.
} 
Second, while scrutinising the tune in terms of the motive and music characteristic, more similarities can be found between this melody arranged by this Chinese composer and a song (Dancing to the moon) from another aboriginal group in Taiwan-Amis. Music example 11 (see Figure 13) is the whole tune of this song (Dancing to the moon). In this music example, it is easy to divide this melody into two parts (bar 1 6 and bar 7 12), and in these two parts, the first two bars are variations and last four bars are the same. In addition, the usage of vocable (ho, hai, ya) in the connective phrase in Evergreen Mountains is widespread in the music in Amis. The lyrics are below:
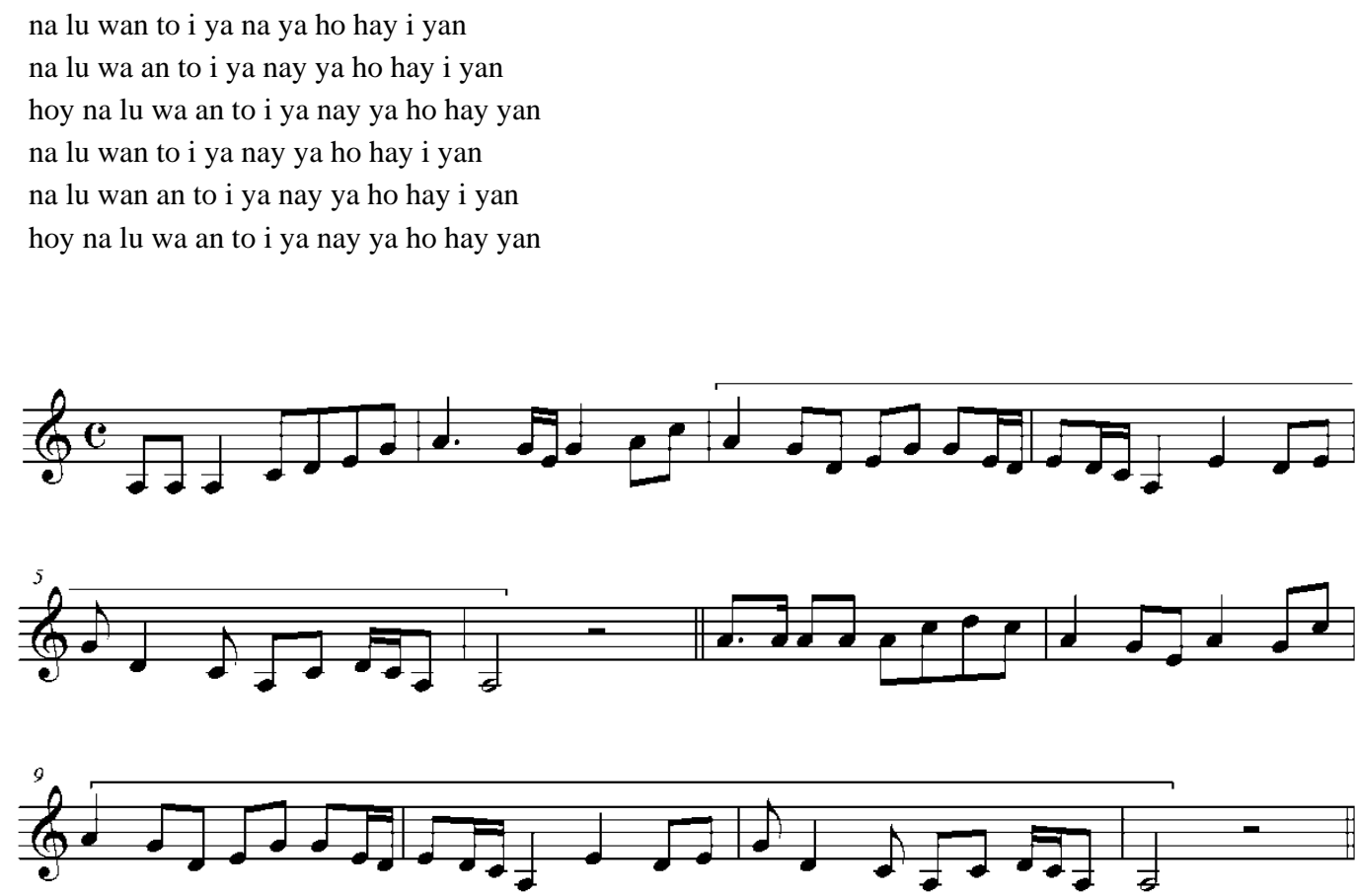

Figure 13. Music example 11: Dancing to the moon in Amis Tribe. ${ }^{6}$

Third, this unfamiliarity results in the remoteness of this putative minority group in this performance. This Chinese composer just can learn a little bit aboriginal music in Taiwan from a songbook released more than 40 years ago, so this unfamiliarity can help her set up a putative minority group in a remote area. The main reason for this is because she just can acquire little information about Taiwanese culture, in particular aboriginal music, under a historical circumstance from 1949. Furthermore, what she can learn is the reinterpretation by others, rather than the real investigation and fieldwork in Taiwan. As a result, Taiwan is replete with her imagination in her mind and the Taiwanese atmosphere she intended to set up in the performance is partly based on her imagination and misunderstanding.

Consequently, this usage of this tune in this performance reflects three points for discussion. On the one hand, she utilised her misunderstanding about aboriginal music in Taiwan to set up her imaginary Taiwan on the stage, and on the other hand, the division and distance between Mainland China and Taiwan provide her with an opportunity to extend her chimerical performance in the performance.

\footnotetext{
${ }^{6}$ See https://www.youtube.com/watch?v=xC_U1KrZGTU.
} 


\section{Conclusion}

From the discussions and reflections above, it is strikingly evident that the two main purposes from this Chinese composer (Zuo Qi-wei) were achieved by her professional skills in composition: setting up relevant atmosphere about a putative aboriginal tribe in the performance and localising this performance. Moreover, three points of the imaginary Taiwan established by this Chinese composer can be reflected by scrutinising the tune in this performance through a comparison with the extant aboriginal music in Taiwan: misunderstanding about aboriginal music, differences and similarities between this tune and some tunes in aboriginal music in Taiwan, and political division between China and Taiwan over an extended period of time.

This localised performance reveals some issues about the process of localisation from a Henan Bangzi Opera to Taiwan Bangzi Opera and the reflections from a viewpoint of a Chinese composer about Taiwan is one of this issues for discussion.

\section{References}

Chang, C. F. (2007). 試論豫劇在台灣的發展與轉化 (A discussion on the development and transformation of Henan Opera in Taiwan). 民俗曲藝, (155), 53-77.

Chen, F. (2003). 論台灣豫劇的現代化與本地化(A study of localisation and modernisation of Henan Opera). In F. Chen and L. M. Yan (Eds.), 台灣䂆劇五十年圖志 (The fifty years of Henan Opera in Taiwan) (pp. 8-23). Taipei, Taiwan: 國光劇團.

Huang, Y. L. (2004). 解嚴後看台灣現代音樂創作中的本土化現象 (The localising phenomena in modern music composition after the cancel of curfew). 關渡音樂學刊, (1), 135-151.

Jiang, J. (1995). 中國戲曲音樂 (Chinese opera music). Beijing: 人民音樂出版社.

Ma, M. H. (2001). A study of the singing of Taiwan Henan Bangzi. (Master thesis, National Taiwan Normal University).

Ma, M. H. (2004). The study of Yuju singing in Taiwan. Performing Arts of Journal, 76-131.

Ma, M. H. (2014a). From Henan Opera to Taiwan Bangzi-Localisation and identity of Taiwan Bangzi. Asian Musicology, 23, 5-36.

Ma, M. H. (2014b). A study of the adaptive ability of a Chinese opera: Three case studies of the localised Taiwan Bangzi. Asian Musicology, 24, 127-170.

Wang, J. X. (1993). 豫劇唱腔音樂概論 (An overview of Yuju singing music). Beijing: 人民音樂出版社.

WU, J. D. (1999). 䖒曲音樂概論 (An overview of Chinese opera music). Beijing: 文化藝術出版社.

Yan, L. M. (2003). 台灣豫劇五十年史略 (A brief history of Henan Opera in Taiwan). In F. Chen and L. M. Yan (Eds.), 台灣 豫劇五十年圖志 (The fifty years of Henan Opera in Taiwan) (pp. 25-35). Taipei, Taiwan: 國光劇團.

Zhao, Z. S. (趙再生). (1993). 河南戲曲音樂概論 (An introduction of Henan Opera). In Z. S. Zhao (Ed.), 中國戲曲音樂大集 成河南卷 (A collection of Chinese opera music-Henan Opera) (p. 61). Beijing: 中國ISBN中心. 